\title{
Fenologia reprodutiva de espécies de bromélias na Serra da Piedade, MG, Brasil ${ }^{1}$
}

\author{
Andréa Rodrigues Marques ${ }^{2,4}$ e José Pires de Lemos Filho ${ }^{3}$
}

Recebido em 7/11/2006. Aceito em 2/07/2007

\begin{abstract}
RESUMO - (Fenologia reprodutiva de espécies de bromélias na Serra da Piedade, MG, Brasil). O presente trabalho objetivou caracterizar a fenologia reprodutiva das espécies de Bromeliaceae da Serra da Piedade. Das dezoito espécies estudadas, $72 \%$ floresceram na estação chuvosa e $28 \%$ na estação seca. Observou-se que a floração das bromélias ao longo do gradiente altitudinal da Serra da Piedade foi seqüencial e influenciada pela sazonalidade das chuvas. A maioria das espécies que ocorrem no habitat xérico pedregoso (acima de $1.400 \mathrm{~m}$ de altitude) apresentou a floração na estação chuvosa, enquanto que três das cinco espécies que ocorrem no ambiente mésico florestal (abaixo de $1.300 \mathrm{~m}$ de altitude) floresceram na estação seca. Espécies simpátricas com características florais semelhantes, como Tillandsia stricta, T. gardneri, Vriesea crassa e V. citrina, também apresentaram floração seqüencial. A dispersão das espécies com sementes aladas (Pitcairnoideae) e plumosas (Tillandsioideae) ocorreu na estação seca, exceto para Dyckia saxatilis e Racinaea aerisincola. Foi observada assincronia na maturação dos frutos e dispersão das sementes entre as bromélias zoocóricas. É provável que essas condições permitam às espécies de bromélias da Serra da Piedade evitar a sobreposição do uso de animais vetores de pólen e de sementes.
\end{abstract}

Palavras-chave: Bromeliaceae, floração, frutificação, dispersão

ABSTRACT - (Reproductive phenology of bromeliad species at Serra da Piedade, Minas Gerais State, Brazil). This work characterizes the phenology of Bromeliaceae species at Serra da Piedade. Of the i8 species studied, $72 \%$ flowered in the rainy season and $28 \%$ in the dry season. We observed sequential flowering of bromeliads along the entire altitudinal gradient at Serra da Piedade; flowering was also influenced by rainfall seasonality. Most species that occur in the rocky xeric habitat (above $1400 \mathrm{~m}$ altitude) flowered during the rainy season, while three of the five species found in the mesic forest (below $1300 \mathrm{~m}$ altitude) flowered in the dry season. Sympatric species with similar floral characteristics, such as Tillandsia stricta, T. gardneri, Vriesea citrina and V. crassa, also flowered sequentially. The dispersal of species with winged seeds (Pitcairnoideae) and plumose seeds (Tillandsioideae) occurred in the dry season, except for Dyckia saxatilis and Racinaea aerisincola. Asynchrony was observed in fruit maturation and seed dispersal among zoochorous bromeliads. These conditions probably allow the bromeliad species of Serra da Piedade to avoid use overlap of animal vectors of pollen and seeds.

Key words: Bromeliaceae, flowering, fruiting, dispersal

\section{Introdução}

Fatores como a precipitação, o estresse hídrico, a irradiação e o fotoperíodo influenciam o comportamento fenológico das plantas (Opler et al. 1976; Reich \& Borchet 1984; Wrigth \& van Schaik 1994; Rivera \& Borchert 2001; Borchert et al. 2004). A abundância de dispersores, de predadores e de polinizadores está freqüentemente associada com a sazonalidade dos eventos vegetativos e reprodutivos das plantas, tanto em nível de comunidade quanto específico (Snow 1965; Janzen 1969; Rathcke \& Lacey 1985; Morellato et al. 1989; Augspurger 1996).
Entre as bromélias têm sido descrito que a sazonalidade das estações chuvosa e seca influenciam grandemente o padrão de floração e afeta a produção, a viabilidade das sementes e o sucesso da germinação (Wright \& Calderon 1995; Benzing 2000). Dados sobre fenologia de bromélias são apresentados em diversos estudos sobre biologia reprodutiva que destacam os eventos florais, os sistemas de cruzamento e o comportamento do polinizador (Sazima et al. 1995a; Martinelli 1997; Sazima et al. 1999; Buzato et al. 2000; Varassin \& Sazima 2000; García-Franco et al. 2001; Wendt et al. 2002; Canela \& Sazima 2003; Lenzi et al. 2006; Machado \& Semir 2006). Os requerimentos

\footnotetext{
1 Parte da Tese de Doutorado do primeiro Autor

2 Centro Federal de Educação Tecnológica de Minas Gerais, CEFET-MG, Av. Amazonas, 5253, 30480-000 Nova Suíça, MG, Brasil

3 Universidade Federal de Minas Gerais, Departamento de Botânica, Av. Antônio Carlos 6627, 31270-110 MG, Brasil

4 Autor para correspondência: andrearmg@gmail.com
} 
de luz e água e os agentes polinizadores e dispersores têm sido reconhecidos como fatores determinantes na floração e frutificação seqüencial e na distribuição espacial das bromélias (Medina 1990; Araújo et al. 1994; Fischer \& Araújo 1995; Benzing 2000).

A família Bromeliaceae é predominantemente neotropical e bem representada na Mata Atlântica do sudeste do Brasil (Fontoura et al. 1991; Benzing 2000). Compreende três subfamílias: Pitcairnoideae com espécies terrestres e sementes aladas dispersadas pelo vento; Bromelioideae, terrestres e epífitas, com frutos carnosos e sementes dispersadas por animais; e Tillandsioideae, predominantemente epífitas com sementes plumosas e dispersadas pelo vento (Benzing 2000).

O presente trabalho objetivou caracterizar a fenologia reprodutiva de 18 espécies de Bromeliaceae da Serra da Piedade. Inserida na área do Quadrilátero Ferrífero de Minas Gerais, a serra possui uma diversificada flora, sujeita à grande pressão antrópica, principalmente pela atividade de mineração. No ambiente da Serra da Piedade os períodos de secas são severos e as espécies de bromélias ocorrem em locais totalmente expostos ao sol ou sombreados, como rupícolas/terrestres ou epífitas, distribuídas em diferentes altitudes. Nesse contexto, foi avaliado se a sazonalidade na distribuição das chuvas e as características morfológicas das bromélias determinam diferentes padrões fenológicos das espécies em habitats xéricos e mésicos ao longo de um gradiente altitudinal.

\section{Material e métodos}

O estudo foi realizado de janeiro/1999 a setembro/2001 na Serra da Piedade (1940'S e 4340'W), Caeté, Minas Gerias. A altitude máxima é de $1.745 \mathrm{~m}$ e a região compreende terrenos representados em quase sua totalidade por itabirito, mas também localmente, quartzo, gnaisse e canga laterítica, que é bastante expressiva na área (Brandão \& Gavilanes 1990). O clima da região é o subtropical de altitude, com estação seca definida, podendo ocorrer geadas nos sítios de maiores altitudes. O período chuvoso na região ocorre entre outubro e março e os meses mais secos, entre abril e setembro (Fig. 1).

Os habitats estudados foram: habitat xérico pedregoso - acima de $1.400 \mathrm{~m}$, caracterizado por solos pedregosos e rasos, com afloramentos rochosos, onde persiste uma vegetação herbácea-arbustiva; habitat mésico altitudinal - acima de $1.400 \mathrm{~m}$, em sítios sujeitos

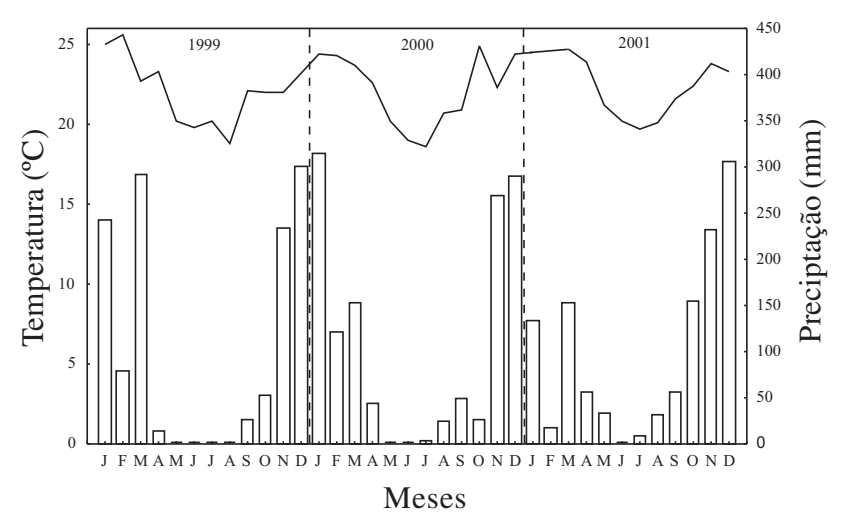

Figura 1. Precipitação total (barra) e temperatura média - valores do décimo quinto dia de cada mês para Belo Horizonte no período entre 1999 e 2001 - dados de precipitação fornecidos pela INFRAERO/ Aeroporto da Pampulha.

à maior freqüência de neblina pela manhã e no final da tarde, constituindo um ambiente mais úmido e sombreado, com vegetação arbustiva-arbórea; habitat mésico florestal - abaixo de $1.300 \mathrm{~m}$, que se caracteriza por um estrato arbóreo predominantemente perenifólio e ambiente sombreado. Os locais para as observações fenológicas foram selecionados em função da facilidade de acesso e representatividade de espécies de bromélias. A altitude foi determinada com um altímetro Ota Keiki Seisakusho e exsicatas das espécies estudadas foram incluídas no herbário BHCB.

Durante as visitas mensais, foram realizadas observações fenológicas em dez genetos de cada espécie, previamente marcados, espaçados entre si por no mínimo $1 \mathrm{~m}$ de distância. Na visita ao campo registrou-se a ocorrência de escapo floral, botão floral, flores, frutos imaturos e maduros para cada espécie e a ocasião da dispersão. O período de dispersão foi considerado a partir da ocorrência de frutos maduros na eminência de dispersão até quando, entre os genetos observados, não mais se verificou a presença de bagas maduras, com dispersão zoocórica no caso da maioria das Bromelioideae e diásporos com plumas (dispersão pogonocórica) ou alados (dispersão pterocórica) no caso das Tillandsioideae e Pticairnoidae, respectivamente. As bagas das Bromelioideae foram consideradas maduras pelo seu aspecto - cor intensa e muita suculência, e os frutos das Tillandsioideae e Pitcairnoideae, no momento em que as cápsulas estavam secas e na eminência de se abrir. Para as espécies de Tillandsia as observações fenológicas foram registradas de janeiro/2000 a setembro/2001, ao passo que para as demais espécies o período foi de janeiro/1999 a setembro/2001. 


\section{Resultados}

Foram registradas, durante todo o período de observações fenológicas, bromélias em floração e frutificação (Fig. 2). O número de espécies em floração foi menor em setembro de $2001(\mathrm{n}=3)$ e maior em novembro e dezembro $(n=9)$. Foi observado o mínimo de espécies em frutificação em julho $(n=5)$ e o máximo em fevereiro $(n=12)$. Em setembro não foram registradas espécies dispersando sementes, ao passo que em abril ocorreu o máximo de espécies nessa fenofase (Fig. 2).

As espécies de Bromelioideae, Aechmea nudicaulis, Neoregelia bahiana e Cryptanthus schwackeanus encontravam-se no habitat xérico pedregoso (Tab.1) e floresceram na mesma época, entre os meses de novembro e fevereiro, enquanto Billbergia amoena e Aechmea lamarchei no habitat mésico florestal, apresentaram período comum de floração entre abril e junho, sendo que a última espécie prolongou a floração até setembro (Fig. 3). Em relação à frutificação, diferente das demais espécies zoocóricas, Billbergia amoena apresentou frutos maduros no mês mais seco - agosto (Fig. 1), A. lamarchei em dezembro e as outras espécies entre março e junho (Fig. 3).

Pitcairnia flammea e Dyckia saxatilis (Pitcairnoidae) foram observadas no habitat xérico pedregoso e mostraram padrões fenológicos distintos (Fig. 3). O início da floração de Pitcairnia flammea ocorreu em dezembro/janeiro e dispersão das sementes foi observada em junho. A presença do escapo floral de Dychia saxatilis foi observada no mês de junho e

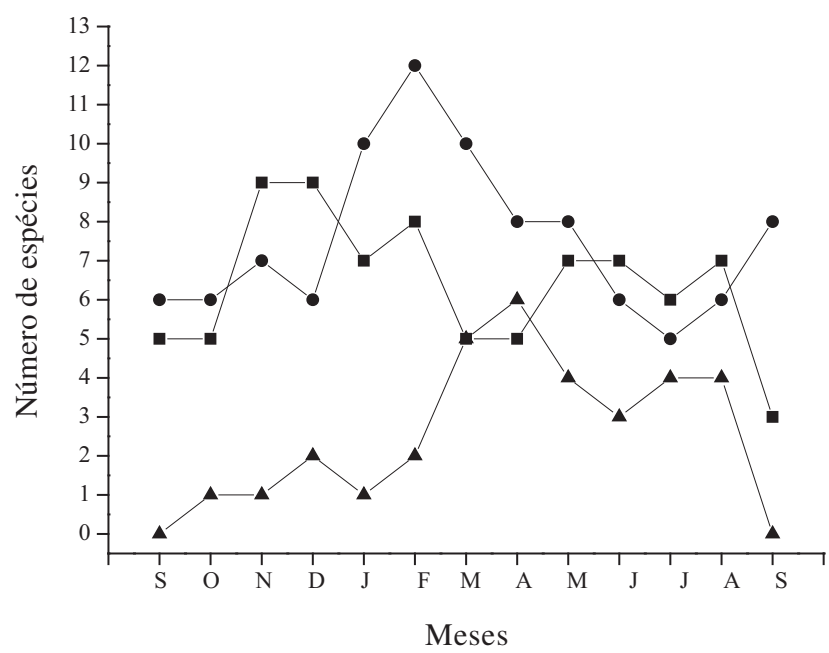

Figura 2. Número de espécies de bromélias ao longo do ano em floração $(\boldsymbol{\square})$, em frutificação $(\bullet)$ e em dispersão (\) na Serra da Piedade, MG, Brasil. a frutificação ocorreu entre os meses de novembro e janeiro (Fig. 3).

Nas populações das espécies de Tillandsioideae foram observados dois grupos fenológicos. O primeiro com espécies - T. gardneri, T. geminiflora, T. stricta, Racinaea aerisincola, Vriesea bituminosa, $V$. friburgensis e $V$. pardalina - que durante todo o período de observação apresentaram alguns dos indivíduos marcados em fenofase reprodutiva. Nesse grupo, no mesmo mês, foram observados indivíduos em diferentes genetos com frutos maduros da floração anterior em dispersão e, em outros genetos, a presença de escapo floral. O período reprodutivo, incluindo floração, frutificação e a dispersão, de Tillandsia gardneri, T. geminiflora, T. stricta e R. aerisincola, foi relativamente longo, iniciando a formação das estruturas reprodutivas no primeiro semestre e encerrando o período de dispersão no ano seguinte. Indivíduos de T. geminiflora permaneceram 10 meses com infrutescências em desenvolvimento culminando na dispersão de suas sementes nos meses mais secos - de maio a julho (Fig. 3). Diferente de todas as Tillandsia, que dispersaram suas sementes plumosas entre março e agosto, período mais seco do ano (Fig. 1), a espécie epífita do habitat mésico altitudinal, $R$. aerisincola, iniciou a dispersão no mês de outubro e encerrou em janeiro, período em que diferentes genetos estavam floridos, em plena estação chuvosa. O segundo grupo apresentou espécies em que por um período não foram observados indivíduos reprodutivos, mesmo entre os genetos não marcados (observação pessoal) - Tillandsia tenuifolia, $V$. citrina, V. crassa e $V$. lubbersii, sendo bem definida a fase reprodutiva dessas espécies (Fig. 3). Tillandsia tenuifolia floresceu de fevereiro a maio e encerrou o período de dispersão de sementes no final de agosto no mesmo ano.

Foram observadas duas espécies epífitas e simpátricas no habitat xérico pedregoso, T. stricta e T. gardneri, com floração seqüencial (Fig. 3). Tillandsia gardneri iniciou a floração em fevereiro e terminou em maio/junho quando iniciou a floração da T. stricta. Ambas as espécies apresentaram flores pequenas azul-arroxeadas e dispersaram suas sementes na mesma época - março e abril (Fig. 3). Duas espécies simpátricas de Vriesea também foram encontradas no habitat xérico pedregoso florescendo sequencialmente com três meses de sobreposição: $V$. crassa em novembro e $V$. citrina em dezembro (Fig. 3). Ambas espécies rupícola/terrestres apresentaram flores amarelas, zigomorfas, tubulosas e morfologicamente 
Tabela 1. Espécies estudadas na Serra da Piedade, MG, Brasil, e seus respectivos hábitos, habitats e altitudes.

\begin{tabular}{|c|c|c|c|}
\hline Espécies & Hábito & Habitat & Altitude (m) \\
\hline \multicolumn{4}{|l|}{ BROMELIOIDEAE } \\
\hline Aechmea lamarchei $\mathrm{Mez}$ & Terrestre & Mésico florestal & 1281 \\
\hline A. nudicaulis (Linnaeus) Grisebach & Rupícola & Xérico pedregoso & 1664 \\
\hline Billbergia amoena (G. Lodd.) Lindley & Terrestre & Mésico florestal & 1281 \\
\hline Cryptanthus schwackeanus $\mathrm{Mez}$ & Rupícola & Xérico pedregoso & 1637 \\
\hline Neoregelia bahiana (Ule) L.B. Smith & Rupícola & Xérico pedregoso & 1664 \\
\hline \multicolumn{4}{|l|}{ TILLANDSIOIDEAE } \\
\hline Racinaea aerisincola (Mez) M.A. Spenc. \& L.B. Smith & Epífitico & Mésico altitudinal & 1637 \\
\hline Tillandsia gardneri Lindley & Epífitico & Xérico pedregoso & 1637 \\
\hline T. geminiflora Brongn & Epífitico & Mésico florestal & 1281 \\
\hline T. stricta Solander & Epífitico & Xérico pedregoso & 1637 \\
\hline T. tenuifolia $($ L.) Linnaeus & Epífitico & Mésico florestal & 1281 \\
\hline Vriesea bituminosa Wawra & Terrestre & Xérico pedregoso & 1691 \\
\hline V. citrina (B.) L.B. Smith & Rupícola & Xérico pedregoso & 1664 \\
\hline V. crassa Mez in Martius & Terrestre & Xérico pedregoso & 1691 \\
\hline V. friburgensis $\mathrm{Mez}$ & Terrestre & Xérico pedregoso/ Mésico altitudinal & 1638 \\
\hline V. pardalina $\mathrm{Mez}$ in Martius & Epífitico & Mésico altitudinal/ Mésico florestal & $1637 / 1281$ \\
\hline V. lubbersii (Baker) E. Morren ex Mez & Epífitico & Mésico florestal & 1281 \\
\hline \multicolumn{4}{|l|}{ PITCAIRNOIDEAE } \\
\hline Dyckia saxatilis $\mathrm{Mez}$ & Rupícola & Xérico pedregoso & 1664 \\
\hline Pitcairnia flammea Lindley & Terrestre & Xérico pedregoso & 1664 \\
\hline
\end{tabular}

semelhantes entre si.

Na Serra da Piedade, a maior parte das espécies $(\mathrm{n}=12)$ que ocorreram no habitat xérico pedregoso e mésico altitudinal (Tab. 1) floreceram na estação chuvosa - A. nudicaulis, C. schwackeanus, N. bahiana, V. citrina, V. crassa, V. friburgensis, $V$. pardalina, $V$. lubbersii, $R$. aerisincola, T. gardneri, P. flammea e D. saxatilis. As bromélias tanque A. nudicaulis, N. bahiana, V. citrina, $V$. crassa e $V$. citrina iniciaram a floração quando os tanques estavam repletos de água e $V$. pardalina e V. friburgensis iniciaram o crescimento do escapo floral antes do período chuvoso. Ainda no habitat xérico pedregoso as bromélias terrestres sem tanque, C. schwackeanus e P. flammea também floresceram na estação chuvosa, quando existe maior disponibilidade de água para as raízes absortivas, ao contrário de D. saxatilis que iniciou a produção de escapo floral na estação seca e abriu suas flores na estação chuvosa. Das cinco espécies que floresceram no período seco, três ocorrem nas menores altitudes da Serra da Piedade, no ambiente mésico florestal - A. lamarchei, B. amoena e T. geminiflora. Billbergia amoena iniciou o crescimento do escapo floral no final da estação chuvosa, quando ainda apresentava o tanque com água. Embora T. geminiflora não apresente tanque e sistema radicular absortivo e seja totalmente dependente dos tricomas peltados na absorção de água e nutrientes, floresceu na estação seca, ao contrário da simpátrica T. tenuifolia que floresceu na estação chuvosa. Tillandsia stricta e $V$. bituminosa, que ocorrem no habitat xérico pedregoso, floresceram durante a estação seca (Fig. 3).

\section{Discussão}

Assim como descrito para muitas espécies arbóreas da caatinga (Machado et al. 1997), da mata atlântica (Morellato et al. 2000) e do cerrado (Batalha \& Mantovani 2001), a floração das bromélias estudadas também mostrou marcantes diferenças em relação à precipitação. Nesse estudo $72 \%$ das espécies de bromélias floresceram durante a estação chuvosa - de outubro a março, e $28 \%$ na estação seca - de abril a setembro. Machado e Semir (2006) observaram proporção semelhante $(70 \%)$ neste período na Mata Atlântica do Parque Estadual Intervales em Ribeirão Grande, SP, assim como Fischer \& Araújo (1995) na região estuarina de São Paulo e Sazima et al. (1996) em todas as comunidades vegetais ornitófilos com que trabalharam em Campos de Jordão.

A sincronia da floração das bromélias na estação chuvosa possibilita uma maior diversificação de oferta de alimento, principalmente para os vetores de pólen. 


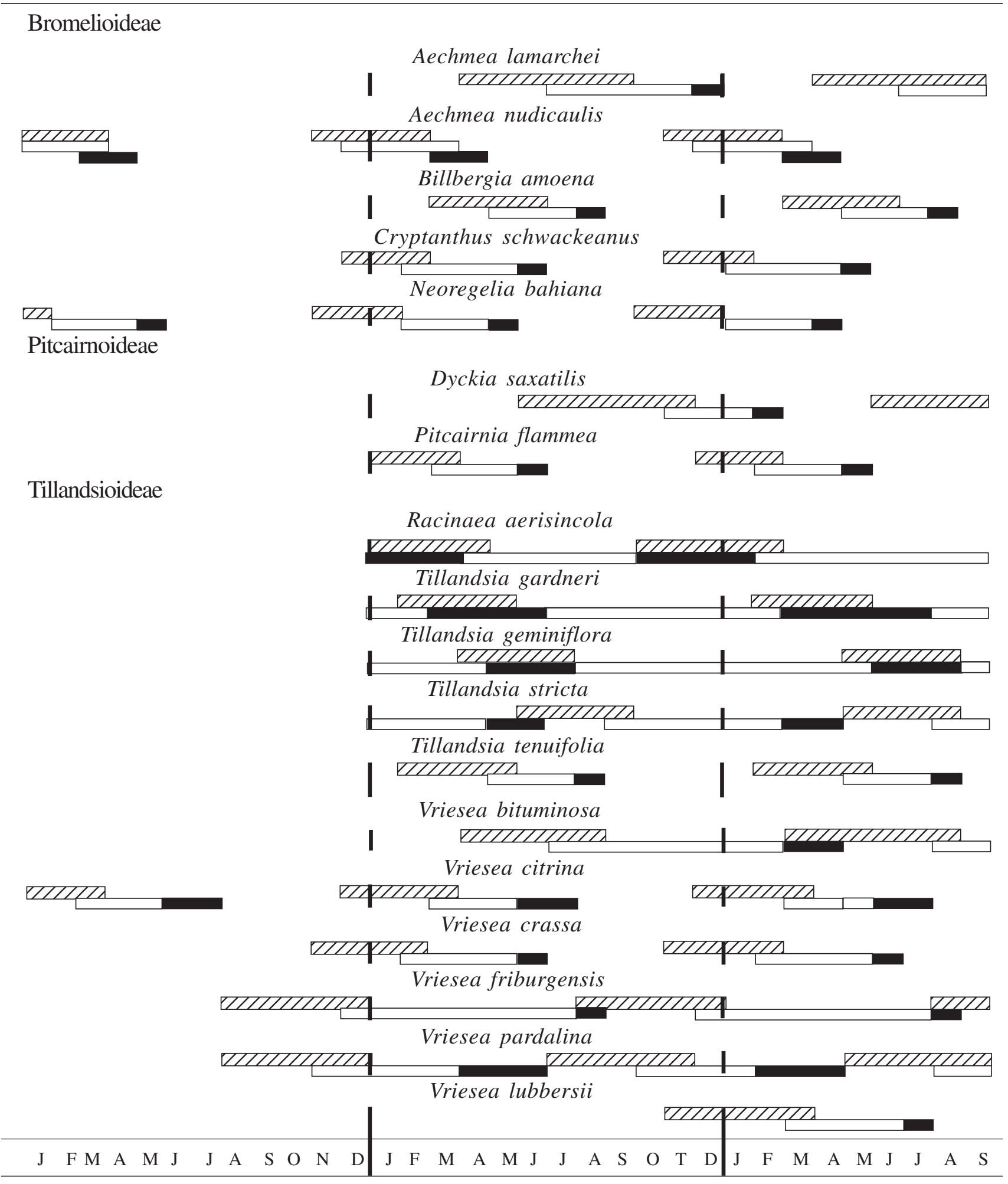

Figura 3. Padrões fenológicos das espécies da subfamília Bromelioideae, Pitcairnoideae e Tillandsioideae na Serra da Piedade, MG, Brasil. O desenvolvimento do escapo floral, botão floral e flores $(\square)$, frutificação ( $\square$ ) e dispersão ( $\square$ ) foram observados de janeiro/1999 a setembro/2001. 
Diversos estudos que apontam os beija-flores como os principais vetores de pólen de $85 \%$ das bromeliáceas nas diferentes comunidades investigadas, sendo as demais espécies visitadas por morcegos e, em menor quantidade, abelhas (Fischer \& Araujo 1995; Sazima et al. 1995b; 1996; Martinelli 1997; Varassin \& Sazima 2000; Canela \& Sazima 2003; Araujo et al. 2004). Vasconcelos \& Lombardi (2001) mostraram que as espécies Aechmea nudicaulis e Pitcairnia flammea da Serra da Piedade são visitadas por beija flores. Machado e Semir (2006) apontaram as espécies Billbergia amoena, Tillandsia geminiflora, T. stricta, T. tenuifolia e Vriesea friburguensis como ornitófilas. Pode-se dizer que grande parte das espécies de bromélias da Serra da Piedade $(n=9)$ é ornitófila, pois além dessas espécies já descritas, era freqüente a visita de aves nas flores de $V$. citrina e $V$. crassa (observação pessoal). Todas essas espécies apresentaram alguns dos atributos descritos para a síndrome da ornitofilia (Faegri \& Pijl 1980; Machado \& Semir 2006): inflorescências expostas, flores tubulosas, cores contrastantes, inodoras e antese diurna. Esses dados sugerem uma considerável diversidade e riqueza de espécies de bromeliáceas ornintófilas em altitudes maiores que $1.500 \mathrm{~m}$. Buzato et al. (2000) registraram 12 espécies no município de Cunha (ca. $1.000 \mathrm{~m}$ ) e sete espécies em Campos de Jordão (ca. 1.500 m). No entanto, a biologia reprodutiva das espécies de bromélias da Serra da Piedade merece maiores estudos.

Algumas espécies simpátricas de Tillandsia e Vriesa apresentaram uma floração seqüencial. Tillandsia gardneri e T. stricta, com flores relativamente semelhantes, pode estar contribuindo com a retenção de uma "imagem de procura" alimentar pelo agente polinizador (Araújo et al. 1994). Segundo os autores a floração seqüiencial pode favorecer o encontro de uma dada espécie em início de floração uma vez que o agente polinizador continua com a imagem de procura já formada durante a exploração da espécie de florada anterior. É provável que o mesmo esteja acontecendo com Vriesea citrina e V. crassa que florescem sequencialmente e mantém a floração sobreposta durante 3 meses expondo flores muito semelhantes aos vetores de pólen. Araújo et al. (1994) observaram um padrão similar para $V$. carinata e $V$. incurvata, que apresentavam um período de sobreposição das florações, e discutiram, baseando-se em Feinsinger (1983), a possibilidade dos indivíduos que florescem nesse período poderem ter seu sucesso reprodutivo diminuído e/ou atuarem como competidores.
A floração das bromélias ao longo do gradiente altitudinal da Serra da Piedade foi seqüencial e contínua, pois durante todos os meses do ano foram registradas bromélias em floração, e influenciada pela sazonalidade das chuvas. Grande parte das bromélias que floresceram na estação chuvosa ocorre em habitat xérico em altitudes superiores a $1.400 \mathrm{~m}$. Características morfológicas das bromélias, como tanque, raízes absortivas e tricomas peltados no período chuvoso, podem otimizar o uso de água favorecendo a floração em ambiente xérico. Entretanto, a floração da maioria das bromélias nas altitudes inferiores a $1.300 \mathrm{~m}$ ocorre no período da seca, e no inverno. A floração nesse ambiente deve coincidir com a maior disponibilidade de polinizadores que nessa época evitariam as freqüentes névoas e as baixas temperaturas dos locais de maior altitude.

A floração seqüencial pode ser uma evidência de adaptação para reduzir a competição pelos vetores do pólen, favorecendo a polinização cruzada (Araújo et al. 1994; Siqueira Filho \& Machado 2001). Esse padrão pode garantir os recursos alimentares para diversos agentes polinizadores durante todo o ano ao longo do gradiente altitudinal da Serra. Além disso, espécies simpátricas com características florais e morfológicas distintas tendem a diminuir a competição pelos vetores de pólen, aumentando a oferta de alimento (Feinsinger 1983; Araújo et al. 1994).

As espécies de Tillandsia foram as que apresentaram período de frutificação mais longo. É provável que o desenvolvimento lento de seus frutos esteja relacionado com a diminuição da umidade do ar, pois a dispersão das espécies de Pitcairnoideae e Tillandsioideae ocorreu principalmente no final da estação seca. Tanto os diásporos com plumas (dispersão pogonocórica) das Tillandsia e Vriesea quanto os alados (dispersão pterocórica) da P. flammea e $D$. saxatilis dependem de baixa umidade do ar para dispersarem (Benzing 2000). Ao contrário das espécies dispersadas pelo vento, Dyckia saxatilis e Racinaea aerisincola mantiveram a dispersão de suas sementes na estação chuvosa. Essa estratégia pode garantir a germinabilidade de sementes e o crescimento de plântulas, que foram observadas imóveis dentro das cápsulas das infrutescências em abscisão da $R$. aerisincola (observação pessoal).

Espécies com bagas macias e de cores vivas como observado para A. nudicaulis e B. amoena, conforme aponta Benzing (2000), sugere que a dispersão seja endozoocórica, através de vertebrados frugívoros, e esse fato pode facilitar o posterior processo de 
germinação. Foi observado assincronia na frutificação das espécies endozoocórica. No habitat xérico pedregoso, Aechmea nudicaulis e N. bahiana frutificaram na estação chuvosa, ao contrário da A. lamarchei e B. amoena, espécies simpátricas do habitat mésico florestal, que frutificaram na estação seca.

A floração seqüencial ao longo do gradiente altitudinal influenciada pela sazonalidade das chuvas e a frutificação assincrônica das espécies zoocóricas permite uma separação espacial e temporal da floração e frutificação de muitas espécies de bromélias evitando a sobreposição do uso de vetores de pólen e de sementes na Serra da Piedade.

\section{Agradecimentos}

Os autores agradecem o apoio financeiro do Conselho Nacional de Desenvolvimento Científico e Tecnológico ( $\mathrm{CNPq})$ e pela bolsa de doutorado cedida pela Fundação de Amparo à Pesquisa de Minas Gerais (FAPEMIG).

\section{Referências bibliográficas}

Araújo, A.C.; Fischer, E.A. \& Sazima, M. 1994. Floração seqüencial e polinização de três espécies de Vriesea (Bromeliaceae) na região de Juréia, sudeste do Brasil. Revista Brasileira de Botânica 17: 113-118.

Araújo, A.C.; Fischer, E. \& Sazima, M. 2004. As bromélias na região do Rio Verde. In: Estação Ecológica JuréiaItatins: Ambiente físico, flora e fauna (O.A.V. Marques \& W. Duleba, eds.). Ribeirão Preto, Editora Holos.

Augspurger, C.K. 1996. A cue for syncronous flowering. Pp.133-150. In: The ecology of tropical rain forest: seasonal rhythms and long-term changes (E.G. Liegh Jr., A.S. Rand \& D. M. Windsor, eds.). Washington, Smithsonian Institution Press.

Batalha, M.A. \& Mantovani, W. 2001. Reproductive phenological patterns of cerrado plant species at the Pé de Gigante Reserve (Santa Rita do Passa Quatro, SP, Brasil): a comparison between the herbaceous and woody floras. Revista Brasileira de Biologia 60: 129-145.

Benzing, D.H. 2000. Bromeliaceae: Profile an Adaptive Radiation. Cambridge, Cambridge University Press.

Benzing, D.H. \& Stiler, K.E. 1998. Dispersão de sementes em bromélias de frutos carnosos: interpretações incorretas e orientações para estudos mais aprofundados. Bromélia 5: 23-25.

Borchert, R.; Meyer, S.A.; Felger, R.S. \& Porter-bolland, L. 2004. Environmental control of flowering periodicity in Costa Rican and Mexican tropical dry forests. Global Ecology and Biogeography 13: 409-425.
Brandão, M. \& Gavilanes, M.L. 1990. Mais uma contribuição para o conhecimento da cadeia do Espinhaço em Minas Gerais (Serra da Piedade) - II. Daphane 1: 26-43.

Buzato, S.; Sazima, M. \& Sazima, I. 2000. Hummingbirdpollinated floras at three Atlantic Forest sites. Biotropica 32: 824-841.

Canela, M.B.F. \& Sazima, M. 2003. Aechmea pectinata: a hummingbird-dependent bromeliad with incospicuous flowers from the rainforest in south-eastern Brazil. Annals of Botany 92: 731-737.

Faegri, K. \& van der Pijl. 1979. The principles of pollination ecology. New York, Pergamon Press.

Feinsinger, P. 1983. Coevolution and pollination. Pp. 282-310. In: Coevolution (D.J. Futuyma \& M. Slatkin, eds.). Suderland, Sinauer Associates.

Fischer, E.A. \& Araújo, A.C. 1995. Spatial organization of a bromeliad community in the Atlantic Rainforest, southeastern Brazil. Journal of Tropical Ecology 11: 550-567.

Fontoura, T.; Costa, A. \& Wendt, T. 1991. Preliminary checklist of the Bromeliaceae of Rio de Janeiro state, Brazil. Selbyana 12: 5-45.

García-Franco, J.G.; Martínez Burgoa, D. \& Pérez, T.M. 2001. Hummningbird flower mites and Tillandsia spp. (Bromeliaceae) polyphagy in a cloud forest of Vera Cruz, Mexico. Biotropica 33: 538-542.

Janzen, D.H. 1969. Seed eaters versus seed size, number, toxicity and dispersal. Evolution 23: 1-27.

Lenzi, M.; Matos, J.Z. \& Orth, A.I. 2006. Variação morfológica de Aechmea lindenii (E. Morren) Baker var. lindenii (Bromeliaceae). Acta Botanica Brasilica 20: 487-500.

Machado, C.G. \& Semir, J. 2006. Fenologia da floração e biologia floral de bromeliáceas ornitófilas de uma área da Mata Atlântica do sudeste brasileiro. Revista Brasileira de Botânica 29: 163-174.

Machado, I.C.S.; Barros, L.M. \& Sampaio, E.V.S.B. 1997. Phenology of caatinga species at Serra Talhada, PE, northeastern Brazil. Biotropica 29: 57-68.

Martinelli, G. 1997. Biologia reprodutiva de Bromeliaceae na Reserva Ecológica de Macaé de Cima. Pp. 213-250. In: Serra de Macaé de Cima: Diversidade Florística e Conservação em Mata Atlântica (H.C. Lima \& R.R. Guedes-Bruni, eds.). Rio de Janeiro, Jardim Botânico do Rio de Janeiro.

Medina, E. 1990. Eco-fisiologia y evolution de lãs Bromeliaceae. Boletin Academia Nacional Ciências, Argentina 59: 72-100.

Morellato, L.P.C.; Rodrigues, R.R.; Leitão Filho, H.F. \& Joly, C.A. 1989. Estudo comparativo da fenologia de espécies arbóreas de floresta de altitude e floresta mesófila semidecídua na Serra do Japi, Jundiaí, São Paulo. Revista Brasileira de Botânica 12: 85-98.

Morellato, L.P.C.; Talora, D.C.; Takahasi, A.; Bencke, C.C.; Romera, E.C. \& Ziparro, V.B. 2000. Phenology of Atlantic Rainforest trees: a comparative study. Biotropica 32: 811-823.

Opler, P.A.; Frankie, G.W. \& Baker, H.G. 1976. Rain fall as a factor in the release, timing and synchronization of anthesis by tropical trees and shrubs. Journal Biogeografic 3: 231-236. 
Reich, P.B. \& Borchet, R. 1984. Water stress ad tree phenology in a tropical dry forest in the lowlands of Costa Rica. Journal of Ecology 72: 61-74.

Rathcke, B. \& Lacey, E.P. 1985. Phenological patterns of terrestrial plants. Annual Review of Ecology and Systematics 16: 179-214.

Rivera, G. \& Borchet, R. 2001. Induction of flowering in tropical trees by a 30 -min reduction in photoperiod: evidence from field observations and herbarium specimens. Tree Physiology 21: 201-212.

Sazima I.; Buzato, S. \& Sazima, M. 1995a. The sawbilled hermit Ramphodon naevius and its flowers in southeastern Brazil. Journal of Ornithology 136: 195-206.

Sazima I.; Buzato, S. \& Sazima, M. 1996. An assemblage of hummingbird-pollinated flowers in Montane Forest in Southeastern Brazil. Botanica Acta 109: 149-160.

Sazima, M.; Buzato, S. \& Sazima, I. 1995b. Bat pollination of Vrisea in southeastern Brazil. Bromélia 2: 29-37.

Sazima, M.; Buzato, S. \& Sazima, I. 1999. Bat-pollinated flower assemblages and bat visitors a two Atlantic Forest sites in Brazil. Annals of Botany 63: 705-712.
Siqueira Filho, J.A. \& Machado, I.C. 2001. Biologia reprodutiva de Canistrum aurantiacum E. Morren (Bromeliaceae) em remanescente da floresta Atlântica, Nordeste do Brasil. Acta Botanica Brasilica 15: 427-443.

Snow, D.W. 1965. A possible selective factor in the evolution of fruiting seasons in tropical forest. Oikos 15: 274-281.

Wendt, T.; Canela, M.B.F.; Klein, D.E. \& Rios, R.I. 2002. Selfing facilitates reproductive isolation among three sympatric species of Pitcairnia (Bromeliaceae). Plant Systematics and Evolution 232: 201-212.

Wrigth, S.J. \& Van schaik, C.P. 1994. Light and the phenology of tropical trees. American Naturalist 143: 192-199.

Wrigth, S.J. \& Calderon, O. 1995. Phylogenetic patterns among tropical flowering phenologies. Journal of Ecology 83: 939-948.

Vasconcelos, M.F. \& Lombardi, J.A. 2001. Hummingbirds and their flowers in the campos rupestres of southern Espinhaço Range, Brazil. Melopsittacus 4: 3-30.

Varassin, I.G. \& Sazima, M. 2000. Recursos de Bromeliaceae utilizados por beija-flores e borboletas em Mata Atlântica no sudeste do Brasil. Boletim do Museu de Biologia Mello Leitão 11/12: 57-70. 